\title{
Has the Price of Motherhood Declined Over Time? A Cross-Cohort Comparison of the Motherhood Wage Penalty
}

Several recent studies have shown a negative association between motherhood and wages. However, an analysis of change over time in the motherhood penalty has not been conducted. Using two cohorts of young women drawn from the 19751985 National Longitudinal Survey of Young Women and the 1986-1998 National Longitudinal Survey of Youth, we explicitly test the relationship between motherhood and wages across two cohorts and examine whether that relationship has changed. Even after controlling for unobserved heterogeneity and human capital variables, each additional child is associated with a negative effect on women's wages. Moreover, our findings suggest that the penalty has not diminished over time.

As the 21 st century begins, women may be approaching equality, but mothers are still far behind. (Ann Crittenden, The Price of Motherhood: Why the Most Important Job in the World Is Still the Least Valued, p. 7)

Population Studies Center, University of Michigan, 426 Thompson Street, P.O. Box 1248, Ann Arbor, Michigan 48104-1248 (savellar@umich.edu).

*Population Studies Center and Department of Sociology, University of Michigan, 426 Thompson Street, P.O. Box 1248, Ann Arbor, Michigan 48104-1248.

Key Words: cohort, gender, labor market, motherhood, wage penalty, work-family.
Since the 1960s, traditional roles specifying husbands as breadwinners and wives as homemakers have been eroding. Social commentators and scientists, in fact, often characterize the past two or three decades as a time of women's increasing economic independence, largely in reference to the marked increase in women's labor market involvement in recent decades. Although women's labor force participation has been increasing for at least a century, the trend accelerated in the 1960s. The proportion of married women with children under age 6 who worked in the labor market (either full-time or part-time) increased from $44 \%$ in 1970 to almost $71 \%$ in 1998 (Casper \& Bianchi, 2001; Spain \& Bianchi, 1996). The gender wage gap has also narrowed, largely driven by cohort replacement (Blau \& Kahn, 2000).

Recently, however, a few studies have identified a phenomenon termed the motherhood penalty, which suggests that the intersection between work and family for women is problematic. The key finding from these studies is that the average wages of mothers are less than those of women without children, even after controlling for human capital, labor market experience, and part-time work status (Anderson, Binder, \& Krause, 2002; Budig \& England, 2001; Korenman \& Neumark, 1991; Taniguchi, 1999; Waldfogel, 1997a).

Although taken together these studies span over 30 years of data (Budig \& England, 2001; 
Korenman \& Neumark, 1991; Waldfogel, 1997a), an explicit analysis of possible change over time-in particular, a decline-in the size of the penalty in a single analysis has not been conducted. This study thus examines the motherhood penalty for two cohorts of young women to determine whether the penalty has significantly shifted across time. To do so, we draw on data from the 1975-1985 waves of the National Longitudinal Survey of Young Women (NLS-YW) and the 1986-1998 waves of National Longitudinal Survey of Youth (NLSY).

\section{BACKGROUND}

The nature of the intersection between motherhood and work outside of the home has shifted over the past few decades. From the 1950s through the 1970s, women who had children often dropped out of the labor force, if they could afford to do so, as the result of several factors. These included public attitudes regarding working mothers, social norms about mothering, discrimination, and the lack of available child care. Consequently, paid labor and children were often incompatible in the lives of women (Casper \& Bianchi, 2001; Spain \& Bianchi, 1996).

Between the 1960s and today, women's labor force participation rate rose dramatically, particularly among White women (Bianchi \& Spain, 1996). Prior to the mid-1960s, most of the increase involved women who were past their childbearing years. Beginning in the late 1960s and 1970s, however, the increase in women's labor force participation spread to younger women, especially mothers of young children (Bianchi \& Spain). By 1990, the employment patterns of White, Hispanic, and Black women had converged, such that women were not systematically leaving the labor force when they reached their childbearing years (Klerman \& Leibowitz, 1999; Spain \& Bianchi, 1996; Yoon \& Waite, 1994). By the year 2000, the majority of mothers (74\%) were in the labor force with more working full-time, rather than part-time (Bachu \& O'Connell, 2001). Related recent trends include wage gains among younger cohorts of women workers, along with some diminishment of the long-standing gender gap in wages, increasing labor force attachment throughout life, delayed childbearing, and some decline in occupational sex segregation beginning in the 1970s (Bianchi, 1994; Casper \& Bianchi, 2001; Jacobs, 1989). Educational investments also increased; in 1990, three quarters of women had
12 years or more of schooling compared with $43 \%$

30 years earlier (Spain \& Bianchi, 1996).

At the same time, numerous studies over the years suggest that parenthood, directly or indirectly, decreases women's earnings and earnings potential (Hanson, 1983; Hudis, 1976; Waite, Haggstrom, \& Kanouse, 1985). In an effort to juggle the dual responsibilities of paid employment and family, for example, women still have more sporadic participation in the labor market than men (Moen, 1992); may choose part-time or shiftwork jobs that may be unrelated to their education and training (Presser \& Baldwin, 1980); and may forsake earnings for "convenient" work attributes, such as flexible hours or proximity to one's home (Stolzenberg \& Waite, 1984).

More recently, a handful of studies has uncovered a more subtle phenomenon: that motherhood impacts women's status in the labor market, not because of part-time work or sporadic participation, but by way of a motherhood penalty to wages. These studies find that even controlling for women's "human capital" (i.e., education, work experience); job characteristics; and unmeasured attributes of women that may be related to pay, mothers earn less than their childless counterparts (Anderson et al., 2002; Budig \& England, 2001; Taniguchi, 1999; Waldfogel, 1997a, 1997b; see Budig \& England for a useful theoretical discussion of the sources of the motherhood penalty).

Estimates of the size of the penalty vary, but the existence of a penalty is replicated across studies using different data, methodologies, measures of motherhood, and varying sets of control variables. For example, studies using a survey called the National Longitudinal Survey of Young Women, which provides coverage of a cohort of women who began entering the labor market in the 1970 s, estimate a motherhood penalty of about $3 \%$ per child (Taniguchi, 1999), or about 3\%-5\% for one child and 5\%-7\% for two or more children (Anderson et al., 2002), after controlling for multiple human capital and sociodemographic variables. Studies based on a similar survey, but one that focuses on a later cohort of women entering the labor force in the 1980s (i.e., the NLSY), suggests the motherhood penalty to be roughly $7 \%$ per child, or $5 \%$ for one child and $10 \%$ for two children, net of various factors that may affect earnings (Budig \& England, 2001; Waldfogel, 1997a).

Given that a wide array of characteristics of the women and jobs are taken into account in these studies, researchers conclude that the re- 
maining or residual penalty to mothers is likely due to some combination of two factors: productivity or employer discrimination, neither of which can be measured with available survey data $\mathrm{Bu}-$ dig \& England, 2001). The idea behind the productivity explanation is that mothers may be less productive on the job than nonmothers because the latter can spend more of their nonemployment time in leisure, rather than in household work and child care (Budig \& England, p. 206). The discrimination explanation is more self-explanatory, encompassing any number of ways that employers treat mothers differently than other women and men in terms of job placement, promotion, or pay levels within jobs (Budig \& England, p. 208).

The goal of our study is straightforward, and that is to answer an important empirical question: Has this price of motherhood declined over time? Specifically, we examine whether there has been a decline over the past few decades in the effect of motherhood on women's wages by formally testing for statistically significant shifts. Unfortunately, substantial differences across studies in model specification, operationalization of motherhood, and model estimation techniques do not allow us to draw any conclusions from existing research about whether and how the motherhood penalty has changed over time. Although two studies (Waldfogel, 1997b; Waldfogel \& Mayer, 2000) use two cohorts of women in a single analysis, their main focus is elsewhere (i.e., maternity leave in one study and gender differences in the low-wage labor market in the other), and the analyses do not formally test for differences over time in the effects of motherhood.

There is some reason to suspect that the penalty has declined. One could speculate that employer discrimination against mothers may have attenuated, as employers no longer have to fear that any woman who has a child will automatically withdraw from the labor market. As more mothers stay in the labor market and the average human capital differences among women with children are narrowed, statistical discrimination should weaken (Marini, 1989); in other words, the perception that mothers are somehow less stable or productive than other employees decreases and employers may begin to treat mothers like other workers. Additionally, in terms of productivity, recent changes may improve the situation for mothers. First, men and husbands have slightly increased their contributions to childcare and housework, suggesting that employed mothers may be getting more real leisure over time (Bian- chi \& Casper, 2000; Casper \& Bianchi, 2001). Secondly, "family friendly" workplace policies may facilitate the balance of work and family, thereby reducing any productivity differentials between mothers and childless women.

One can also, of course, construct scenarios in which the motherhood penalty remains steady or widens. For example, employers may now demand more from all employees, as the traditional male model of work behavior is expected of and replicated by more women and mothers. Even if a woman does not alter her work behavior after the birth of a child, an employer may be more suspicious of any deviations from the "proper" worker (i.e., the man whose family obligations had no impact on his work behavior) than in previous years. Additionally, statistical discrimination may continue if negative stereotypes regarding mothers' employment persist despite changes in behavior.

\section{Current Investigation}

This study compares the motherhood penalty for two cohorts of women and systematically tests whether effects have changed over time. Although past research shows that a mother penalty exists, we do not yet know whether there has been temporal change in the penalty.

Following past research, we estimate two types of models to examine changes in the size and significance of the penalty over time, while controlling for basic sociodemographic and human capital characteristics (e.g., Anderson et al., 2002; Budig \& England, 2001; Waldfogel, 1997a). First, we estimate pooled ordinary least squares (OLS) models; this type of model compares women who do not have children at a given point in time with those who do (net of other independent variables). Second, we estimate a fixed-effects model that controls for stable (i.e., unchanging), but unmeasured, differences among individuals. As argued by Budig and England, fixed-effects models "eliminate bias created by failure to include controls for unmeasured personal characteristics" (p. 213). For example, if childless women differ from mothers in terms of an unmeasured characteristic such as ambition, fixed-effects models will eliminate this bias. Essentially, if a penalty is found when estimating the fixed-effects models, this implies that the penalty is due neither to factors that we measure in the models nor to stable unmeasured ones. 


\section{METHOD}

\section{Data}

We draw the two cohorts of women used in the analysis from the NLS-YW and the NLSY. The NLS-YW is comprised of women who were between the ages of 14 and 24 in 1968. The sample is designed to be nationally representative; Black women were oversampled. Sample attrition has been relatively small (CHRR, 1997), and 18 waves of the survey had been conducted as of 1995. The more recent cohort is drawn from the NLSY, which began in 1979 with a nationally representative sample of 12,686 men and women between the ages of 14 and 21, including oversamples of Black and Hispanic participants. The respondents were interviewed each year until 1994, when the survey shifted to a biennial design (CHRR, 1999).

These data are well suited to our research question. As large samples of two birth cohorts, rather than cross-sections of the population at any age, they permit temporal comparisons. Inferences about change over time require that comparisons be age-specific (Menard, 1991; Ryder 1965; see Smock, 1993, and Sweeney, 2002, for similar use of the NLS data to examine cohort change). To attain as much age comparability as possible between the two cohorts, we restrict the earlier cohort to only include information from 1975 through 1985 and the later one from 1986 through 1998. In 1975, the women in the NLS-YW range from 21 to 33 years of age, when most have likely completed their schooling and are thus poised to enter the workforce. By 1985, the women are 31 to 42 years, with the oldest women nearing the end of their childbearing ages. Similarly, the women in the NLSY are 21-29 years old in 1986 and 33-41 years old in 1998. Although by limiting the data to include only women who are 21 years of age or older we are excluding early childbearers, this underestimation will occur in both cohorts and will thus have no effect on the assessment of the change over time.

The sample is restricted to include only women with at least 2 years of reported wages. At least two observations are necessary to calculate fixedeffects models, and we use this rule for the OLS models as well for comparability. This restriction results in the loss of a substantial minority of respondents (799 respondents in the early cohort, 130 respondents in the late cohort), and thus possible selection bias. For example, women may ex- perience or anticipate the wage penalty and simply withdraw from the labor force, and women who are most negatively affected by the penalty may be most likely to withdraw. Although unfortunate, this bias is true of all research that has used fixedeffects models to examine the motherhood wage penalty (Budig \& England, 2001; Taniguchi, 1999; Waldfogel, 1997a). Moreover, our central aim is to investigate change in the penalty across time, and whatever bias exists is likely to be there for both cohorts. A general implication is that calculations of the penalty may be conservative in their estimation, because they only capture the penalty among women who work outside of the home in at least 2 years.

Our final sample size is 3,032 women in the earlier cohort and 5,213 in the later cohort. Arranged in person-year records as the unit of analysis as needed for the statistical models, our sample size is 55,369 records: 14,282 person-years in the early cohort, and 41,087 in the late cohort. In the early cohort, a woman on average contributes 5.40 person-years (minimum 2, maximum 7); in the more recent cohort, women average 9.03 person-years (minimum 2, maximum 11).

\section{Measures}

Following past research, our dependent variable is the $\log$ of hourly wages; the natural log is used in order to normalize the distribution of wages. Extremely low wages (less than \$1) were dropped (292 records), and extremely high wages (greater than \$200) were top-coded at \$200, then logged (54 records).

We operationalize the key independent variable, motherhood, with a continuous measure of number of children. This measure has also been used in past research and has the advantage of simplicity and ease of interpretation (Budig \& England, 2001, p. 217). The children may be biological, adopted, or stepchildren living (or who have lived) in a woman's household. Thus, for the purposes of this analysis, a woman who has given birth but has never lived with her child is not considered a mother, whereas a nonbiological mother who lives with step- or adopted children is considered a mother. It is important to underscore that the former is rare: The vast majority of children under age 18 do live with their biological mothers (Casper \& Bianchi, 2001; Fields, 2001). Additionally, past findings suggest that the motherhood penalty is likely produced at least in part from lower productivity or employer discrimination 
(Budig \& England); these factors are arguably affected more by the presence of children in the household, rather than biological children who have always lived elsewhere.

The other independent variables were selected because of their reported significance in past research, their centrality to the wage determination process, and our ability to attain consistency in measures over the two cohorts. We include dichotomous variables for the highest completed year of schooling; a continuous measure of age and age squared; and years of part-time (fewer than 35 hours/week) and full-time (35 hours or more/week) work experience as well as their squared terms. We measure part-time and fulltime work experience separately because part-time experience may be less valuable than full-time experience (see Waldfogel, 1997a). Because mothers tend to have more part-time experience than childless women, they will likely be disproportionately affected by the lower returns generated by parttime work histories. There is incomplete accounting of work experience between the years 1973 and 1975 in the NLS-YW; we thus follow imputation procedures outlined by Waldfogel (1997a, pp. 210-211) to help construct our measure.

Additionally, we include a series of dichotomous measures representing marital status (married, divorced, separated, and widowed) with never married as the reference category and a measure of being Black, with non-Black as the reference category. However, the variable for race is only included in the OLS regression because constant terms drop out of fixed-effects models.

Finally, to evaluate cohort change, we construct an interaction term that multiplies number of children by a dichotomous variable for cohort. To test the change over time, we combined the two cohorts and created a dummy variable for the cohort, interacting this with all of the independent variables in the model, including the continuous children variables. We test whether this coefficient is statistically significant in a full, pooled model (i.e., cohort is interacted with all of the independent variables in the model), allowing us to examine whether and in what direction the motherhood penalty has altered over time. Coefficients for the interaction terms can be found in the Appendix.

\section{Models}

We first present results from a pooled, OLS model in which women have a record for every year that they responded to the survey. This model compares women with themselves at other points in time as well as to other women (see Anderson et al., 2002; Budig \& England, 2001; Waldfogel, 1997a). Structuring the data in this way allows the incorporation of time-varying characteristics of individuals in order to fully exploit the longitudinal information (Allison, 1984). Note that because each woman contributes more than one record to the data, the data are clustered, meaning that the observations are not independent. We thus also correct the standard errors; if not corrected, the standard errors would be too small, sometimes by a factor of two or more (StataCorp, 1997). Finally, to prevent women who contribute more observations from disproportionately affecting the results, the OLS coefficients have been weighted by the inverse of the number of times a woman appears in the data.

We next present one-way (across person) fixedeffect models, which are well known for their ability to control for stable, unobserved heterogeneity-the possibility that unmeasured factors may affect both motherhood and wages. In fixedeffects models, the variables are calculated as deviations from individual means. The model is as follows:

$$
\left(y_{i t}-\bar{y}_{i}\right)=\left(x_{i t}-\bar{x}_{i}\right) \beta+\left(\varepsilon_{i t}-\bar{\varepsilon}_{i}\right)
$$

where $i$ indexes individuals, $t$ refers to time, and $x$ symbolizes a matrix of independent variables. $\varepsilon$ denotes the residual that is homoscedastic with a mean of zero. The coefficients of the fixed-effects models should be interpreted as comparisons of a woman with herself at some other point in time; for example, contrasting her wages when she was childless with her wages after she became a mother. Essentially by comparing a woman with herself, we eliminate the possibility that the OLS analysis is confounded by contrasting childless women with mothers; this is important if mothers are different from childless women in some unmeasured way. This is also important in order to accurately capture the motherhood penalty over time because it allows for the possibility that the type of women who become mothers has shifted across cohorts not only in measured but also in unmeasured ways. However, it is important to underscore that fixed-effects models only take account of stable, unmeasured traits. If a particular woman's motivation or ambition changes over time, this model will not hold these effects constant. 


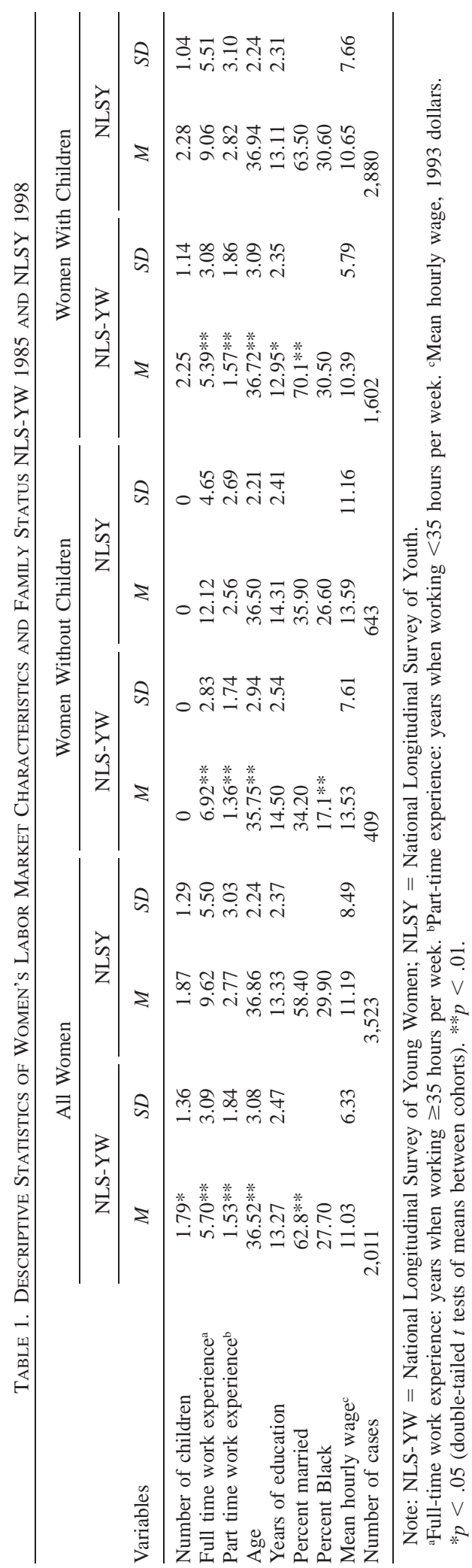

\section{RESULTS}

\section{Descriptive Statistics}

Table 1 displays descriptive statistics for the two samples for the last respective year of data included in the analysis (1985 for the NLS-YW and 1998 for the NLSY). The first set of columns refers to all women, whereas the next two sets subdivide the samples into women without and women with children, respectively.

Among all women, the later cohort has a significantly higher number of children (1.87 vs. 1.79). This is driven by a smaller percentage of childless women; however, a two-tailed $t$ test indicates that the number of children among mothers has remained stable across two cohorts. The mean number of children for mothers is 2.25 for women in the NLS-YW and 2.28 for the NLSY. Education has also remained constant at a little over 13 years of schooling on average.

In contrast, as expected from recent trends, work experience has increased significantly. The average number of years of full-time experience is 5.70 for women in the early cohort, but 9.62 for women in the more recent sample. Similarly, women in the earlier cohort have only 1.53 years of average part-time experience, compared with 2.77 years for women in the NLSY. Despite the increase in work experience, however, the mean hourly wage (in 1993) dollars has remained stable: $\$ 11.03$ in the earlier and \$11.19 in the more recent cohort ( $p$-value for two-tailed test $=.47$ ).

As the second and third sets of columns suggest, in both cohorts, women without children are more advantaged in terms of wages, education, and work experience. At the same time, the gap between mothers and childless women appears to be closing on some variables. For instance, the difference in hourly wage between childless women and mothers has lessened, from $\$ 3.14$ for the NLS-YW to \$2.94 for the NLSY (in 1993 dollars). Additionally, in terms of years of educational attainment, the gap between mothers and childless women used to be over a year and a half, declining to 1.2 years in the more recent cohort. In contrast, disparities in work experience are increasing. In the early cohort, mothers had on average 1.53 fewer years of full-time work experience; in the late cohort, the difference was 3.06.

\section{Multivariate Results}

To examine the motherhood penalty, Table 2 presents results from the pooled OLS models. The 
Table 2. Pooled Ordinary Least Squares (OlS) Models Regressing Natural Log of Wages on Various FAMILY AND LABOR MARKET CHARACTERISTICS

\begin{tabular}{|c|c|c|c|c|c|}
\hline \multirow[b]{2}{*}{ Variables } & \multicolumn{2}{|c|}{ NLS-YW 1975-1985 } & \multicolumn{2}{|c|}{ NLSY 1986-1998 } & \multirow{2}{*}{$\begin{array}{c}\text { Tests of } \\
\text { Differences in } \\
\text { Coefficients }\end{array}$} \\
\hline & $B$ & $S E B$ & $B$ & $S E B$ & \\
\hline Number of children & $-.016^{* *}$ & .005 & $-.10^{*}$ & .005 & $n s$ \\
\hline Full-time work experience & $.059 * *$ & .007 & $.068 *$ & .003 & $n s$ \\
\hline Full-time work experience squared & -.0008 & .0007 & $-.001 * *$ & .0002 & $n s$ \\
\hline Part-time work experience & -.002 & .009 & .002 & .004 & $n s$ \\
\hline Part-time work experience squared & $.004 *$ & .002 & $.003 * *$ & .0005 & $n s$ \\
\hline Age & $.038 * *$ & .012 & .015 & .010 & $n s$ \\
\hline Age squared & $-.0006^{* *}$ & .0002 & $-.0004 *$ & .0002 & $n s$ \\
\hline$<12$ years education & $-.108 * *$ & .017 & $-.090 * *$ & .014 & $n s$ \\
\hline $13-15$ years education & $.144 * *$ & .016 & $.161 * *$ & .012 & $n s$ \\
\hline$\geq 16$ years education & $.345^{* *}$ & .016 & $.473 * *$ & .015 & $* *$ \\
\hline Married & .026 & .016 & .002 & .011 & $n s$ \\
\hline Divorced/separated/widowed & $.051 * *$ & .019 & $.030 *$ & .013 & $n s$ \\
\hline Black & $-.060 * *$ & .013 & $-.063 * *$ & .011 & $n s$ \\
\hline Intercept & $1.30 * *$ & .183 & $1.55^{* *}$ & .147 & - \\
\hline$R^{2}$ & .25 & & .30 & & .29 \\
\hline$F$ & $126.67 * *$ & & $381.74 * *$ & & $253.07 * *$ \\
\hline Number of observations & 14,282 & & 41,087 & & 55,369 \\
\hline
\end{tabular}

Note: The dependent variable is the natural log of the hourly wage. Only women with at least 2 years of reported wages are included in the analysis. Data are weighed with the inverse of the number of times a respondent appears in the data. The reference categories are 12 years of education and never married. NLS-YW = National Longitudinal Survey of Young Women; NLSY $=$ National Longitudinal Survey of Youth.

$* p<.05$. ** $p<.01$.

third column shows whether there are statistically significant cohort differences in the effects of the independent variables. The coefficient for number of children indicates that, net of other variables, each child depressed the wages of women in the early cohort by about $1.6 \%$ and about $1 \%$ for women in the more recent cohort. These coefficients are both statistically significant. The last column shows, however, that the motherhood penalty has not declined significantly over time.

The other variables in the equations generally perform as expected, with full-time work experience, although not part-time, increasing the log of a woman's hourly wage. Schooling is also positively associated with wages, and women with less than 12 years of education have significantly lower wages than those who graduated from high school. Compared with the never married, the formerly married earn more, but the currently married earn about the same, and being Black has a negative effect on hourly wages. In terms of change over time, the effects have been fairly constant, with the exception of 16 or more years of education, which has become significantly more valuable across time.

Table 3 shows the results of fixed-effects models. As the first row of the table shows, children are associated with about a $3.8 \%$ penalty in the early cohort; the effect of children in the more recent cohort is quite similar at 3.3\%. Tested explicitly, the decrease across cohorts is not statistically significant. Note that the fixed-effect coefficients for children are greater than their counterparts in the OLS regression models, which implies that unobserved heterogeneity suppresses the coefficients in the OLS models. Thus the OLS models may be underestimating the motherhood penalty.

With some slight variations from the OLS results, the other variables in the model generally performed as expected. Work experience, both full and part-time, is positively associated with wages, although the squared term is negative. This suggests that after a certain point, an additional year of work experience does not yield as much of an increase in wages as at lower levels of experience. Education only has a significant effect for women with 16 or more years of schooling. In the early cohort, being married or having been married appears to decrease one's wages relative to the never married, whereas in the late cohort it increases women's wages. When tested for change across cohorts, the results imply the effects of marital status have increased. Age is only significant in 
Table 3. Fixed Effects Models Regressing Natural Log of Wages on Various Family and Labor MARKET CHARACTERISTICS

\begin{tabular}{|c|c|c|c|c|c|}
\hline \multirow[b]{2}{*}{ Variables } & \multicolumn{2}{|c|}{ NLS-YW 1975-1985 } & \multicolumn{2}{|c|}{ NLSY 1986-1998 } & \multirow{2}{*}{$\begin{array}{c}\text { Tests of } \\
\text { Differences in } \\
\text { Coefficients }\end{array}$} \\
\hline & $B$ & $S E B$ & $B$ & $S E B$ & \\
\hline Number of children & $-.038 * *$ & .006 & $-.033 * *$ & .005 & $n s$ \\
\hline Full-time work experience & $.082 * *$ & .006 & $-.067 * *$ & .003 & $n s$ \\
\hline Full-time work experience squared & $-.002 * *$ & .0004 & $-.002 * *$ & .0001 & $n s$ \\
\hline Part-time work experience & $.036 * *$ & .010 & $.031 * *$ & .005 & $n s$ \\
\hline Part-time work experience squared & .002 & .001 & $-.0008^{*}$ & .0004 & $n s$ \\
\hline Age & $.040 * *$ & .008 & .009 & .007 & $*$ \\
\hline Age squared & $-.0007 * *$ & .0001 & $-.0002 *$ & .0001 & $*$ \\
\hline$<12$ years education & .057 & .030 & -.0007 & .023 & $n s$ \\
\hline $13-15$ years education & .018 & .018 & .011 & .016 & $n s$ \\
\hline$\geq 16$ years education & $.163 * *$ & .030 & $.239 * *$ & .023 & $n s$ \\
\hline Married & $-.031 *$ & .014 & $.028 * *$ & .009 & $* *$ \\
\hline Divorced/separated/widowed & -.031 & .017 & $.049 * *$ & .011 & $* *$ \\
\hline Intercept & $1.30 * *$ & .118 & $1.66^{* *}$ & .100 & - \\
\hline$F$ & $112.90 * *$ & & $263.46^{* *}$ & & $181.21 * *$ \\
\hline Number of observations & 14,282 & & 41,087 & & 55,369 \\
\hline
\end{tabular}

Note: The dependent variable is the deviation of the natural log hourly wage from the mean natural log hourly wage for the individual. The reference categories are 12 years of education and never married. NLS-YW = National Longitudinal Survey of Young Women; NLSY = National Longitudinal Survey of Youth.

$* p<.05 . * * p<.01$.

the early cohort, with the interaction terms indicating that the effect of age has declined across cohorts.

\section{DISCUSSION}

In recent decades, one of the most dramatic changes in work behavior has been the movement of mothers into paid employment. Whereas in previous periods women who had children, especially White, middle-class women, largely left the labor market, now the majority of mothers across the social class spectrum remain employed. As the work behavior of mothers and childless women converge, we might expect a priori that the motherhood penalty would decline over time. Not only are human capital differences diminished, but factors such as employer discrimination could have attenuated. For example, if employers become less concerned that their female employees will eventually give birth and leave their jobs, they may not relegate women, particularly mothers, to lower level, dead-end jobs.

Drawing on data from the 1975-1985 NLSYW and the 1986-1998 NLSY, this study examined whether the motherhood penalty declined over time. Our findings indicate that it has not. For both cohorts of women, taking into account an array of variables, children decrease women's wages significantly, and this penalty has been quite stable. Moreover, this result holds in both OLS and fixed-effects models.

Thus, although women's labor force patterns have changed and become more similar to men's, our analysis suggests that critical disparities remain. Given evidence that marriage and children, if anything, increase men's earnings (Cohen, 2002; Daniel, 1995; Waite, 1995), our findings suggest that paid work and family is still more a mother's struggle than that of two parents. Hochschild's (1989) description of a "stalled revolution" where women have begun to take on the traditional male roles, yet are still responsible for the "female" duties such as housework and childcare, remains apt. Our findings are also consistent with recent research demonstrating that although married women are working longer into their pregnancies and returning to work sooner, they continue to be much more likely to reduce their employment surrounding the transition to parenthood than married men. In fact, married men's employment levels remain unaffected by the birth of a child (Lundberg \& Rose, 2000; Noonan, 2001).

Further, in a quantitative analysis such as this one, differences in variables affecting pay such as work experience are swept away so that we are left with two comparable groups; yet mothers and childless women (or men) often do not have the same observable characteristics. Given the current 
environment, even mothers who want to continue their education or labor force participation may have an extremely difficult time doing so. Additionally, women may decide to allocate more of their time at home after experiencing barriers in their workplace (Gerson, 1985), as a discouraging situation may quash a woman's workplace ambitions. "Choices" are thus firmly entrenched in the context of viability; if a woman cannot get ahead in a job or share the child care equally with a partner, her choices are limited.

Finally, it is essential to recognize that although individual mothers incur these costs, the benefits of children and motherhood are much more widely dispersed. Mothers who, despite the obstacles, are able to combine paid work and family life are making important contributions to the paid economy. Even more, the children they are raising are, as some social scientists have argued, "public goods"; society profits greatly from future generations being reared as stable, well-adjusted adults, as well as future employees and taxpayers (England \& Folbre, 1991; Folbre, 1994). Our study shows that, rather than being compensated, women continue to be penalized for these contributions.

There are a few limitations in our research. First, it would be beneficial to have a longer time span between the cohorts of women. Our two cohorts entered the labor force approximately 10 years apart; greater change in the penalty, and perhaps a decline, might have been observed with a larger spread among the cohorts. Another limitation is that we were only able to follow the sample into their early 40s. It would be informative to analyze women later in the life course when most no longer have children at home because we do not yet know if the disadvantages associated with motherhood will continue long after children are no longer a daily responsibility. Third, we did not impute wages because our goal was to document the actual penalty over time. However, as a result, we lost a greater proportion of the earlier cohort of women who did not have at least 2 years of wages. Imputations could provide counterfactual evidence that the penalty for the earlier cohort would have been even more severe if more mothers had stayed in the labor market.

Overall, our findings lead us to conclude that if women continue to be the parents largely responsible for child care, mothers will be unable to catch up to childless women or to men without such responsibilities. As the majority of women continue to have children, the motherhood penalty is far reaching and will likely remain a critical contributor to gender inequality in the workplace.

\section{Note}

An earlier version of this article was presented at the annual meeting of the American Sociological Association in Anaheim, California, 2001. We are grateful to Laurie Morgan and Yu Xie for their helpful comments and assistance. This research was supported by grants from the National Institute of Child Health and Human Development (P30-HD10003 and T32-HD07339).

\section{REFERENCES}

Allison, P. D. (1984). Event history analysis: Regression for longitudinal event data. Newbury Park: Sage.

Anderson, D., Binder, M., \& Krause, K. (2002). The motherhood wage penalty: Which mothers pay it and why? The American Economic Review, 92, 354-358.

Bachu, A., \& O'Connell, M. (2001). Fertility of American women: June 2000 (Current Populations Reports, P20-543RV). Washington, DC: U.S. Census Bureau.

Bianchi, S. (1994). The changing economic roles of men and women. In R. Farley (Ed.), State of the union: America in the 1990s (Vol. I, pp. 107-154). New York: Russell Sage Foundation.

Bianchi, S., \& Casper, L. M. (2000). American families (Population Bulletin 55). Washington, DC: Population Reference Bureau.

Bianchi, S., \& Spain, D. (1996). Women, work, and family in America (Population Bulletin 51). Washington, DC: Population Reference Bureau.

Blau, F. D., \& Kahn, L. M. (2000). Gender differences in pay. Journal of Economic Perspectives, 14, 75-99.

Budig, M. J., \& England, P. (2001). The wage penalty for motherhood. American Sociological Review, 66, 204-225.

Casper, L. M., \& Bianchi, S. (2001). Continuity and change in the American family. Thousand Oaks, CA: Sage.

Center for Human Resource Research. (1997). The national longitudinal surveys young women users' guide. Columbus, OH: U.S. Department of Labor.

Center for Human Resource Research. (1999). The national longitudinal surveys NLSY79 user's guide. Columbus, OH: U.S. Department of Labor.

Cohen, P. N. (2002). Cohabitation and the declining marriage premium for men. Work and Occupations, 29, 346-363.

Crittenden, A. (2001). The price of motherhood: Why the most important job in the world is still the least valued. New York: Henry Holt.

Daniel, K. (1995). The marriage premium. In K. Ierulli (Ed.), The new economics of human behavior (pp. 113-125). New York: Cambridge University Press.

England, P., \& Folbre, N. (1991). Who should pay for the kids? Annals of the American Academy of Political and Social Science, 563, 194-207.

Fields, J. (2001). Living arrangements of children: Fall 1996. Washington, DC: U.S. Census Bureau.

Folbre, N. (1994). Who pays for the kids? Gender and the structure of constraint. London: Routledge. 
Gerson, K. (1985). Hard choices: How women decide about work, career, and motherhood. Berkeley, CA: University of California Press.

Hanson, S. (1983). A family life-cycle approach to the socioeconomic attainment of working women. Journal of Marriage and the Family, 45, 323-338.

Hochschild, A. (1989). The second shift. New York: Avon Books.

Hudis, P. (1976). Commitment to work and family: Marital-status differences in women's earnings. Journal of Marriage and the Family, 38, 267-278.

Jacobs, J. A. (1989). Revolving doors: Sex segregation and women's careers. Stanford, CA: Stanford University Press.

Klerman, J. A., \& Leibowitz, A. (1999). Job continuity among new mothers. Demography, 36, 145-155.

Korenman, S., \& Neumark, D. (1991). Marriage, motherhood, and wages. The Journal of Human Resources, 27, 233-255.

Lundberg, S., \& Rose, E. (2000). Parenthood and the earnings of married men and women. Labour Economics, 689-710.

Marini, M. M. (1989). Sex differences in earnings in the United States. Annual Review of Sociology, 15, 343-380.

Menard, S. (1991). Longitudinal research. Newbury Park, CA: Sage.

Moen, P. (1992). Women's two roles: A contemporary dilemma. New York: Auborn House.

Noonan, M. C. (2001). The changing effects of parenthood on men's and women's employment. Unpublished dissertation, University of Michigan, Ann Arbor.

Presser, H. B., \& Baldwin, W. (1980). Child care as a constraint on employment. American Journal of Sociology, 85, 1202-1213.

Ryder, N. B. (1965). The cohort as a concept in the study of social change. American Sociological Review, 30, 843-861.
Smock, P. J. (1993). The economic costs of marital disruption for young women over the past two decades. Demography, 30, 353-371.

Spain, D., \& Bianchi, S. M. (1996). Balancing act: Motherhood, marriage, and employment among American women. New York: Russell Sage Foundation.

StataCorp. (1997). Stata statistical software: Release 5.0. College Station, TX: Stata Corporation.

Stolzenberg, R., \& Waite, L. J. (1984). Local labor markets, children and labor force participation of wives. Demography, 21, 157-170.

Sweeney, M. M. (2002). Two decades of family change: The shifting economic foundations of marriage. American Sociological Review, 67, 132-147.

Taniguchi, H. (1999). The timing of childbearing and women's wages. Journal of Marriage and the Family, 61, 1008-1019.

Waite, L. J. (1995). Does marriage matter? Demography, 32, 483-507.

Waite, L. J., Haggstrom, G., \& Kanouse, D. (1985). Changes in employment activities of new parents. American Sociological Review, 50, 263-272.

Waldfogel, J. (1997a). The effect of children on women's wages. American Sociological Review, 62, 209 217.

Waldfogel, J. (1997b). Working mothers then and now: A cross-cohort analysis of the effects of maternity leave on women's pay. In R. G. Ehrenberg (Ed.), Gender and family issues in the workplace (pp. 92126). New York: Russell Sage Foundation.

Waldfogel, J., \& Mayer, S. E. (2000). Gender differences in the low-wage labor market. In D. Card (Ed.), Finding jobs: Work and welfare reform (pp. 193232). New York: Russell Sage Foundation.

Yoon, Y. H., \& Waite, L. J. (1994). Converging employment patterns of Black, White and Hispanic women: Return to work after first birth. Journal of Marriage and the Family, 56, 209-217. 
APPENDIX

Interaction Coefficients for TABles 2 and 3, Multiplying Dichotomous Cohort Variables by Other INDEPENDENT VARIABLES

\begin{tabular}{|c|c|c|c|c|}
\hline \multirow[b]{2}{*}{ Variables } & \multicolumn{2}{|c|}{ OLS (Table 2) } & \multicolumn{2}{|c|}{ Fixed Effects (Table 3) } \\
\hline & $B$ & $S E B$ & $B$ & $S E B$ \\
\hline Cohort $^{\mathrm{a}}$ & .247 & .235 & - & - \\
\hline Number of children $\times$ cohort & .005 & .007 & .005 & .010 \\
\hline Full-time work experience $\times$ cohort & .008 & .007 & -.016 & .009 \\
\hline Full-time work experience squared $\times$ cohort & -.0004 & .0007 & -.0001 & .0006 \\
\hline Part-time work experience $\times$ cohort & .004 & .010 & -.006 & .014 \\
\hline Part-time work experience squared $\times$ cohort & -.002 & .002 & -.003 & .002 \\
\hline Age $\times$ cohort & -.023 & .016 & $-.031 *$ & .012 \\
\hline Age squared $\times$ cohort & .0002 & .0003 & $.0005 *$ & .0002 \\
\hline$<12$ years education $\times$ cohort & .018 & .022 & -.056 & .046 \\
\hline $13-15$ years education $\times$ cohort & .017 & .020 & -.007 & .029 \\
\hline$\geq 16$ years education $\times$ cohort & $.128 * *$ & .022 & .076 & .046 \\
\hline Married $\times$ cohort & -.024 & .019 & $.059 * *$ & .021 \\
\hline Divorced/separated/widowed $\times$ cohort & -.021 & .023 & $.080 * *$ & .025 \\
\hline Black $\times$ cohort & -.004 & .017 & - & - \\
\hline Number of observations & 55,369 & & 55,369 & \\
\hline
\end{tabular}

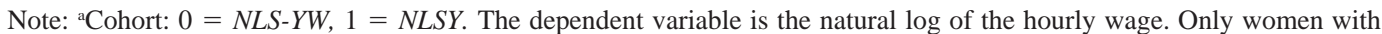
at least 2 years of reported wages are included in the analysis. Data are weighted with the inverse of the number of times a respondent appears in the data. The reference categories are 12 years of education and never married. OLS $=$ ordinary least squares; NLS-YW = National Longitudinal Survey of Young Women; NLSY = National Longitudinal Survey of Youth.

$$
* p<.05 . * * p<.01 \text {. }
$$

